\title{
Hydrogen Generation from Biomass-Derived Sugar Alcohols via the Aqueous-Phase Carbohydrate Reforming (ACR) Process
}

\author{
Report Submitted to: U.S. Department of Energy \\ DE-FC36-04GO14258
}

Final Report - June 30, 2006

Submitted by: Energy Center of Wisconsin

455 Science Drive, Suite 200, Madison, WI 53711

608.238.4601

Subcontractors: Virent Energy Systems, Inc. and Archer Daniels Midland Company 


\title{
Final Technical Report DOE Project DE-FG36-04G014258
}

\author{
Hydrogen Generation from Biomass-Derived Sugar Alcohols via the Aqueous Phase \\ Reforming (APR) Process
}

Report Period: October, 2004 through March 31, 2006

\section{Executive Summary}

Under this effort, Virent was funded to provide a cost effective means for generation of hydrogen from sugar alcohols, such as sorbitol, from the Aqueous Phase Reforming (APR) process. The patented APR process provides a revolutionary method for generation of hydrogen from sugar and sugar alcohols. This was the first detailed study for Virent on converting a glucose-derived compound, such as sorbitol, into hydrogen and alkanes. The studies conducted hereunder validated that the process can produce cost effective combinations of hydrogen and/or fuel gas. It also enabled Virent to develop a number of catalysts that are useful for conversion of sorbitol and other candidate feedstocks. This work led to the filing of a patent for the novel catalysts developed under this proposal. In the end, Virent completed the development of the catalytic reactor system necessary for reforming sorbitol, tested this reactor system with glycerol, designed, constructed, and tested a subscale reactor system that generated over 2000 thermal watts of hydrogen-rich fuel gas from the aqueous-phase reforming of glycerol. This work was invaluable in the development of the initial demonstration unit for the APR process described in further detail below.

\section{Objectives and Results}

This project involved the investigation and development of catalysts and reactor systems that will be cost-effective to generate hydrogen from potential sorbitol streams. The intention was to identify the required catalysts and reactors systems as well as the design, construction, and operation of a 300 grams per hour hydrogen system. Virent was able to accomplish this objective with a system that generates $2.2 \mathrm{kgs}$ an hour of gas containing both hydrogen and alkanes that relied directly on the work performed under this grant. This system, funded in part by the local Madison utility, Madison, Gas \& Electric (MGE), is described further in the report. The design and development of this system should provide the necessary scale-up information for the generation of hydrogen from cornderived sorbitol.

The objective of this effort was to demonstrate the ability to produce hydrogen from the sugar alcohols derived from glucose. This objective was also accomplished. The hydrogenrich fuel produced from sorbitol can be utilized to feed gas-fired turbines, internal combustion engines (consistent with the demonstration described below) or it can be returned to the electric grid. 
Additional details on the tasks, milestones and outcomes are provided below.

This was a joint project with work performed by the Energy Center of Wisconsin (The Center), Virent Energy Systems (Virent) and Archer Daniels Midland Company (ADM).

\section{Summary of Activities by Quarters}

\section{FIRST QUARTER SUMMARY - October - December 2004}

Work focused on the investigation of reaction conditions for sorbitol reforming, and on interpretation of analytical results of feedstock sampling.

\section{Reaction Conditions for High Conversion}

Past work prior to the start of this effort had demonstrated that use of carbon supports with particles size distributions smaller than 18-40 mesh improved catalyst and reactor performance. Supports with particle size distributions of 120-200 mesh and $\sim 75$ mesh have been tested. The 75 mesh carbon was originally reported as being 200 mesh; it is actually $200 \mu \mathrm{m}$ which is equivalent to $\sim 75 \mathrm{mesh}$. Even on these smaller particle size carbon supports, mass transfer limitations still seemed to be controlling reforming of sorbitol.

The possibility of heat transfer limiting Sorbitol reforming was investigated by changing the reactor diameter. Figure 1 compares results for the Virent A catalyst formulation on the commercial 75 mesh support in a standard diameter reactor (0.334" I.D.) to the same catalyst in a smaller diameter reactor (0.085" I.D.).

Figure 1. Comparison of Different ID Tube Reactors (Virent A on 75 mesh carbon, 30\% Sorbitol, WHSV 8.0)

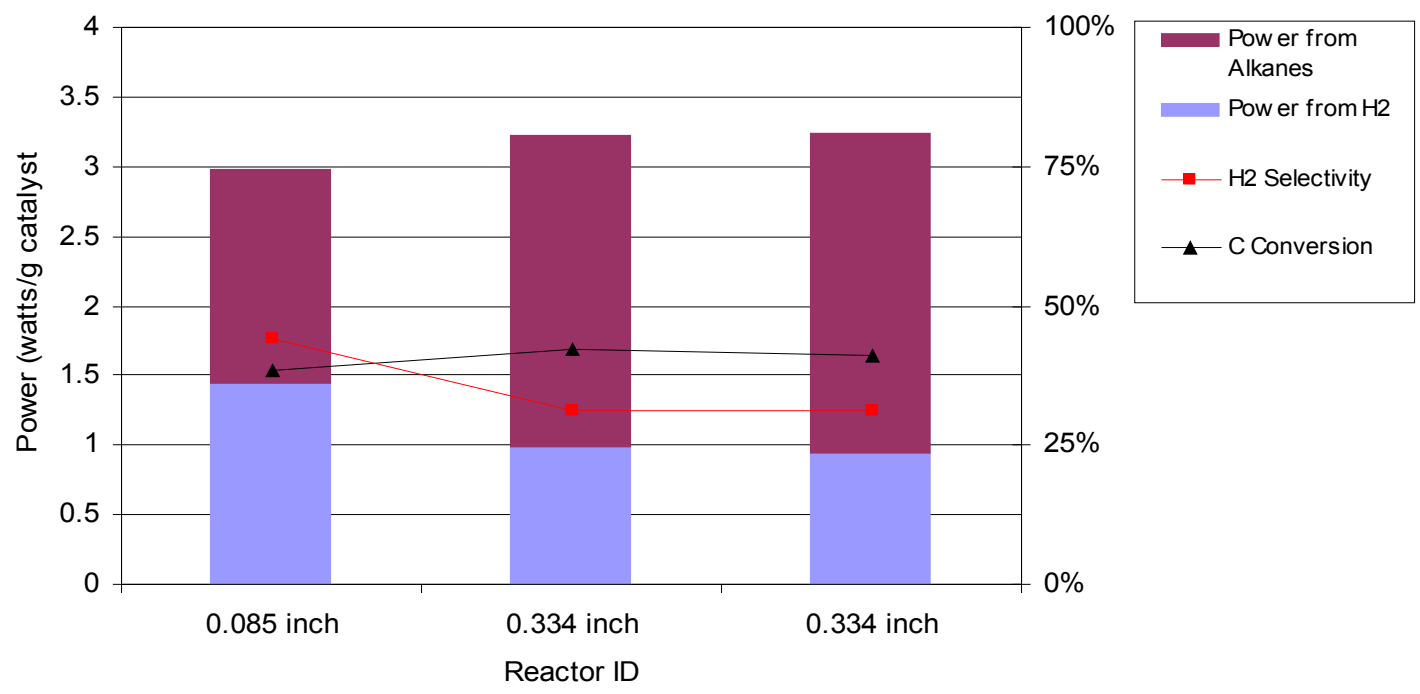

Both reactors were operated at a WHSV of $\sim 8.0$ because this was the lowest WHSV which could be achieved, due to less catalyst mass $(0.86 \mathrm{~g}$ vs. $10.7 \mathrm{~g})$, in the smaller ID reactor. 
This higher WHSV experiment resulted in lower conversion of the sorbitol to gaseous products than we have observed at lower WHSV. Conversion for the smaller ID reactor was $38 \%$ and $42 \%$ for the larger reactor. Total power produced was also slightly higher for the larger reactor, 3.2 vs. 3.0 watts/g catalyst. However, hydrogen selectivity was higher in the smaller ID reactor, $44 \%$ vs. $31 \%$. This resulted in almost half the power in small diameter reactor coming from hydrogen ( 1.44 watt/g catalyst) while for the large diameter reactor only about of the total power was from hydrogen ( 0.94 watt $/ \mathrm{g}$ catalyst). Increased hydrogen production in the small diameter reactor is most likely due to better heat transfer throughout the entire catalyst bed which allows this endothermic reaction to progress further.

\section{ADM Analytical Results}

Due to limitations of Virent's analytical capabilities, we have been estimating conversion of Sorbitol as the amount of Sorbitol fed into the reactor less the amount converted into gaseous carbon containing products $\left(\mathrm{CO}_{2}\right.$ and alkanes). This method of estimation assumes that all, or at least most, of the carbon containing material remaining in the aqueous solution is still sorbitol. To determine the validity of this assumption, several samples of reacted solution were submitted to ADM for analysis. Results from analysis of the first samples were received in late November; additional results were received in December. Surprisingly, in all but one sample no sorbitol was found to be remaining in solution. This means that in most cases the reaction conditions did achieve 100\% conversion of Sorbitol, but that conversion was not exclusively into the desired products; other reaction pathways were competing, yielding other products. The list of products observed by ADM is complex; we are working to understand the pathways which yield different products and the conditions which influence these side-reaction pathways. Samples from additional experiments, designed to understand these side-reactions, were submitted to ADM for analysis in December.

\section{Conclusions}

Our standard diameter reactor system is heat transfer limited.

Our efforts to find APR reaction conditions which achieve complete conversion of sorbitol were to some extent unnecessary since almost all conditions tested did achieve this goal. It has now been determined that side-reactions, resulting in unwanted products, are consuming the sorbitol we assumed had not been converted. Now the problem is to find conditions which improve the selectivity to carbon conversion to gas. The reaction conditions we have studied should help our understanding of these side-reactions and eventually control these reactions.

Most of the compounds observed by ADM should be combustible. To the extent that they cannot be eliminated, it should be possible to vaporize and burn them as a heat source for the reaction. Some compounds may have significant value, and be worth recovering in some applications.

\section{SECOND QUARTER SUMMARY - January - March 2005}

\section{ACTIVITIES AND ACCOMPLISHMENTS FOR JANUARY - MARCH, 2005}


Work focused on the interpretation of analytical results from ADM, testing catalyst formulations, and investigation of reaction conditions for sorbitol. In addition two catalyst formulations were tested for stability. Below is a detailed description of the work performed.

\section{Catalyst Stability Trials}

Two catalyst formulations, Virent A and $\mathrm{P}$, were tested for stability while reforming sorbitol over longer periods of time. Results for Virent A are summarized in Figure 1.

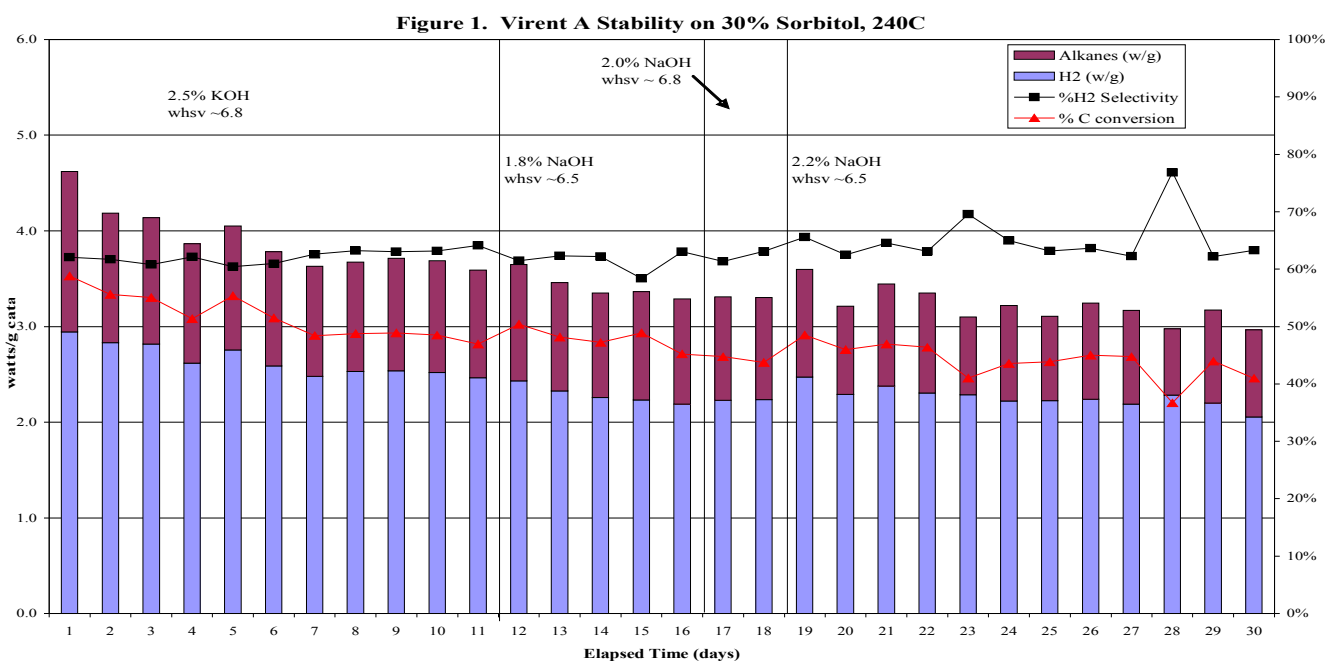

The initial conditions for this trial, days 1 to 11 , included $30 \%$ sorbitol feed with $2.5 \%$ $\mathrm{KOH}$ added, WHSV $\sim 6.8$, and $240^{\circ} \mathrm{C}$ reaction temperature. There was some initial degradation of activity over the first 2-3 days, followed by a slower, but continuous, decline in activity. On day 11 the source of hydroxide was switched from $\mathrm{KOH}$ to $\mathrm{NaOH}$; the initial concentration of $1.8 \%$ was selected to give the same molarity of hydroxide as the $2.5 \% \mathrm{KOH}$. The $\mathrm{NaOH}$ concentration was increased on day 16 to $2.0 \%$ and subsequently, on day 18 , to $2.2 \%$ in order to raise the $\mathrm{pH}$ of the product solution to slightly greater than 6 ; matching the initial $\mathrm{pH}$ using $\mathrm{KOH}$. Catalyst activity generally continued to decrease slowly from day 12 through day 30; the final total power was $\sim 3$ watts/g catalyst compared to an initial total power of $\sim 4$ watts/g catalyst. There appears to be no significant difference in the effect of $\mathrm{KOH}$ and $\mathrm{NaOH}$.

Results of the stability trial for formulation $\mathrm{P}$ are summarized in Figure 2. Several times during this trial other conditions were investigated; these days, for example days 8 and 9 , are not illustrated in Figure 2. Catalyst performance was somewhat inconsistent over the first week of operation. Catalyst activity generally decreased slowly from day 10 through day 38 ; the final total power was slightly less than 3.5 watts/g catalyst compared to an initial total power of $\sim 4.5 \mathrm{watts} / \mathrm{g}$ catalyst. 


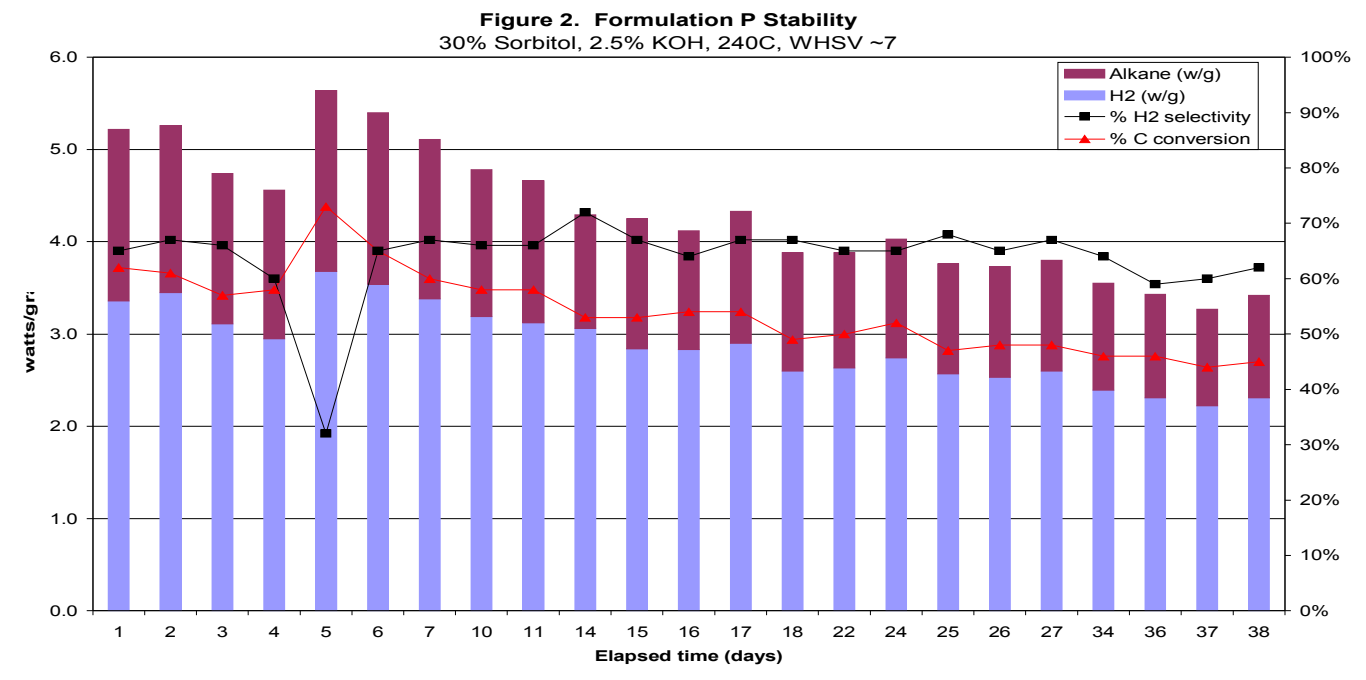

Non-Gaseous Products

The products generated when Sorbitol is reformed over three additional catalysts have been analyzed by ADM; Figures 3A and 3B summarize the non-gaseous products formed with and without $\mathrm{KOH}$ respectively. Formulations $\mathrm{A}$ and $\mathrm{P}$ are included in the Figures as benchmarks. Catalyst activity for these formulations was reported in February.
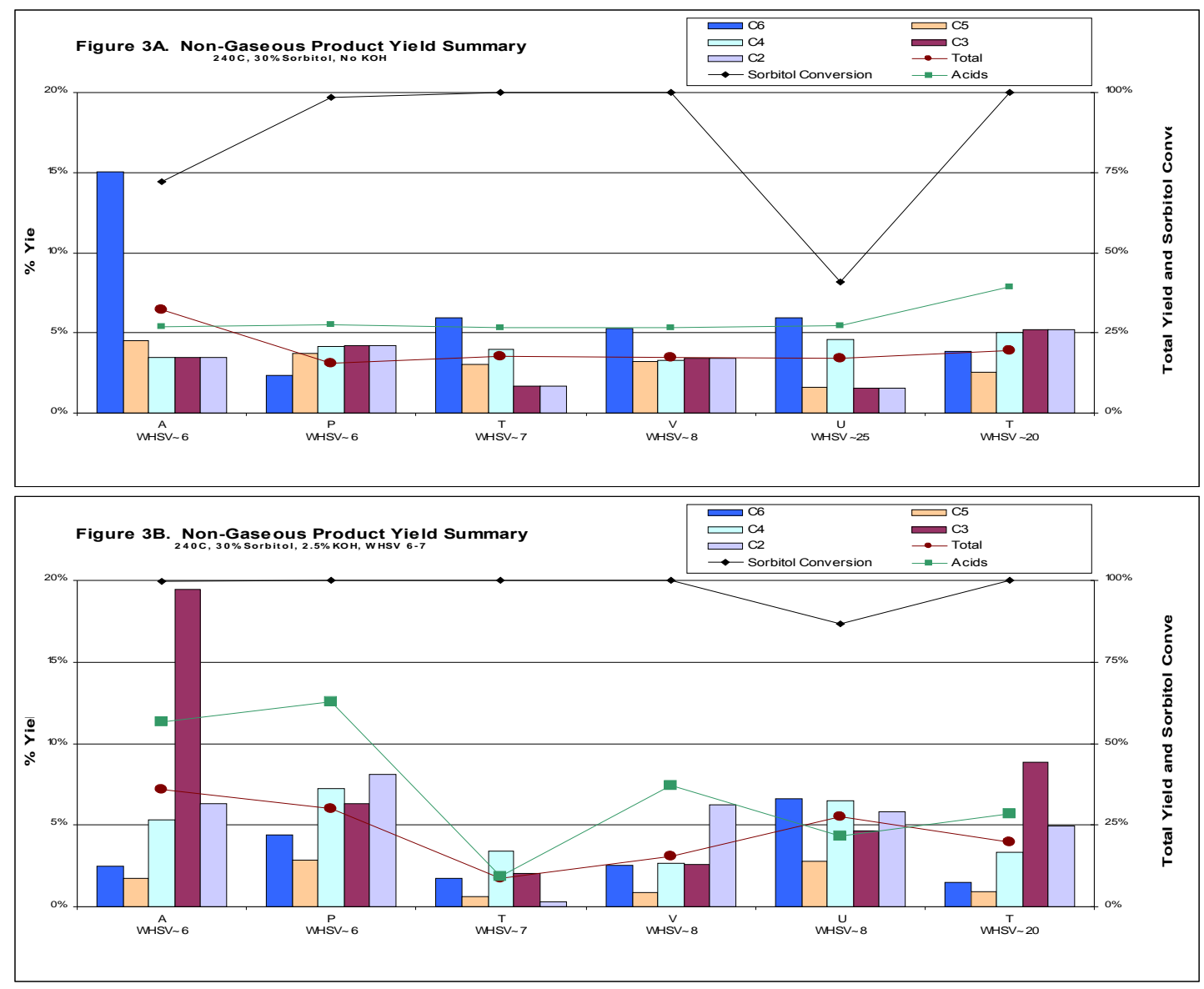
Conversion of sorbitol was $100 \%$ even without $\mathrm{KOH}$, except for formulation $\mathrm{U}$ which was $41 \%$ conversion without $\mathrm{KOH}$ and $87 \%$ with $\mathrm{KOH}$. Acid and Total non-gaseous products were lowest for formulation T with $\mathrm{KOH}$ at WHSV of 7. Unlike other formulations the yield of organic acids decreased with addition of $\mathrm{KOH}$ for formulation $\mathrm{T}$; formulation $\mathrm{U}$ also showed a, less significant, decrease, while formulation $\mathrm{V}$ behaved more typically producing more acids when $\mathrm{KOH}$ was present.

\section{Catalyst formulation Testing}

Nine new catalyst formulations were tested in February; Figure 4 summarizes the results for these formulations.

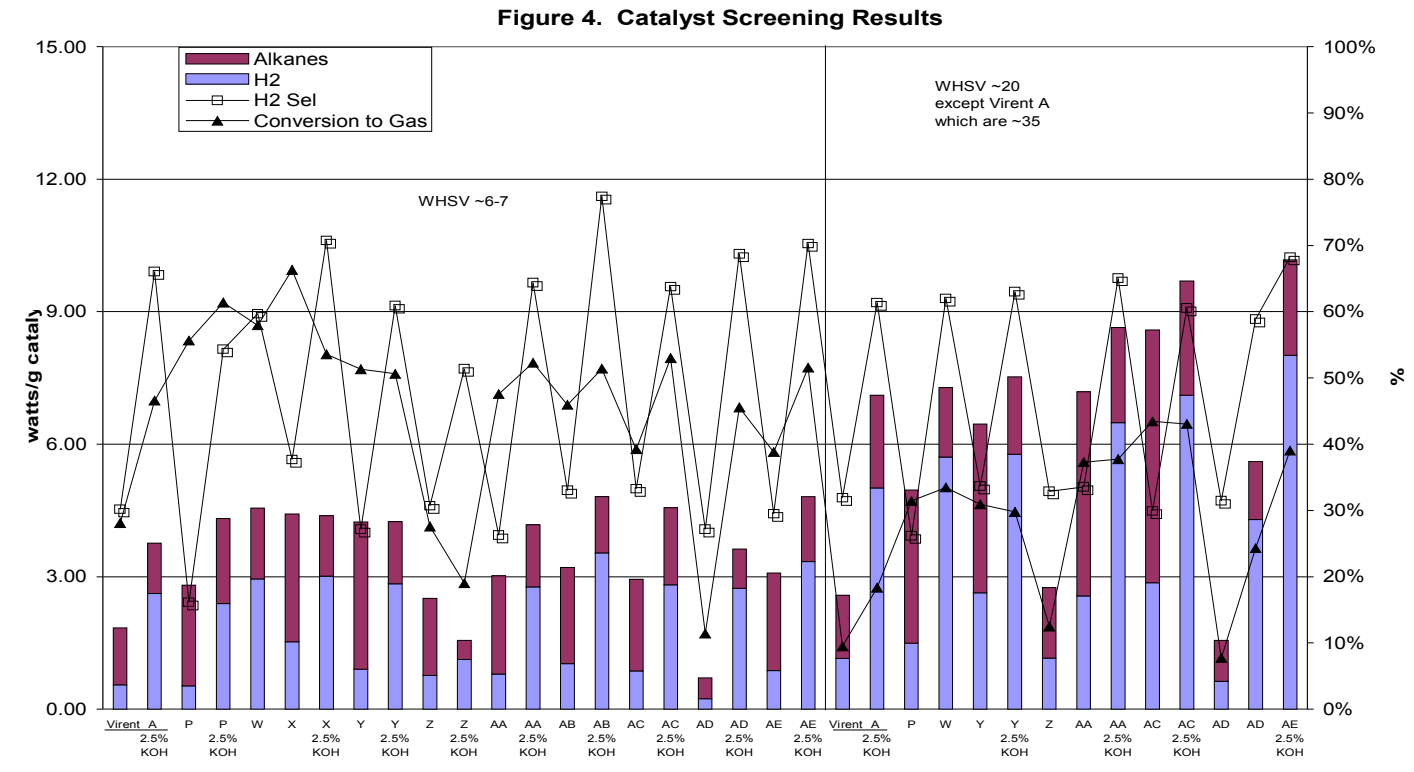

Several of these formulations performed better than Virent A and were comparable or better than formulation $\mathrm{P}$. As noted in February for formulations $\mathrm{S}$ and $\mathrm{T}$, power output was not increased by addition of $\mathrm{KOH}$ for formulations $\mathrm{X}$ and $\mathrm{Y}$ while hydrogen selectivity did improve.

\section{Conclusions}

Catalyst stability testing for Virent A and formulation P show both of these formulations slowly lose activity when hydroxide is combined with the sorbitol substrate.

The source of hydroxide does not affect catalyst performance; less expensive $\mathrm{NaOH}$ would be an acceptable substitute for $\mathrm{KOH}$.

Several catalyst formulations which perform better that Virent A have now been identified. Some of these formulations generate fewer non-gaseous products, especially without $\mathrm{KOH}$. Some of these formulations have higher $\mathrm{C} 6$ fragmentation activity without $\mathrm{KOH}$ suggesting it may be possible to reduce or eliminate a basic co-catalyst for reforming sorbitol.

\section{THIRD QUARTER SUMMARY - April - June 2005}


Work continued on testing catalyst formulations. In addition, several trial catalyst preparations submitted by Virent's catalyst provider were evaluated. Virent's catalyst provider will supply Virent with catalyst for the electric power generation pilot system; this catalyst will be based on the Virent $P$ formulation.

\section{Description of Activities}

Catalyst Formulation Testing

Twelve more catalyst formulations were tested in June; Figures 1A and 1B summarize the results for these formulations.
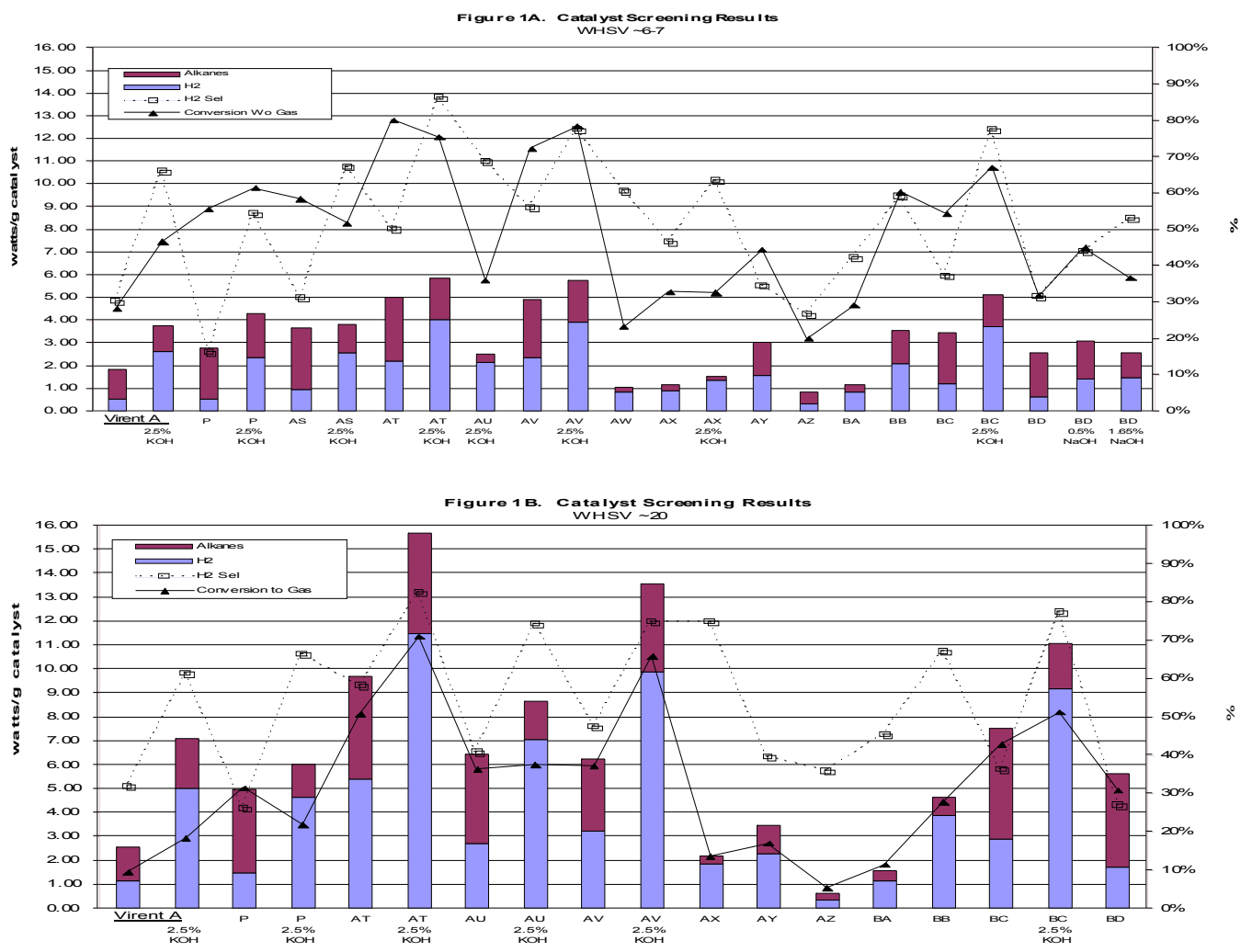

Formulations AS, AT, AV, AY, BB, BC, and BD performed similarly or better than Virent A and Virent $\mathrm{P}$ at both WHSV. Formulation AU was similar at high WHSV, but did not perform as well at low WHSV. The other formulations (AW, AX, AZ, and BA) did not perform as well as Virent A and Virent P.

Supplier Catalyst Testing

Six catalyst preparations have been tested; figures $2 \mathrm{~A}$ and $2 \mathrm{~B}$ summarize the results for these preparations. 

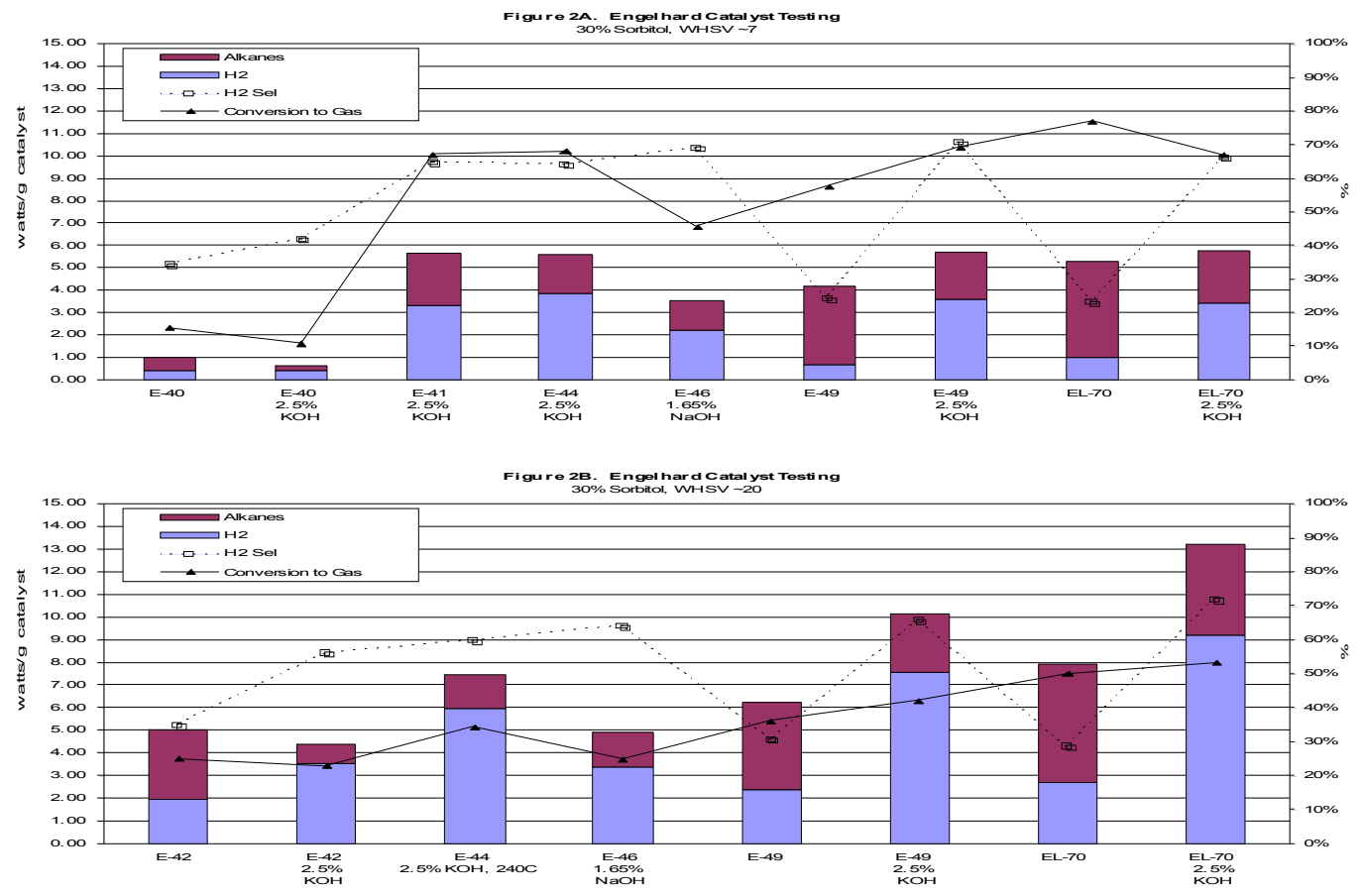

The best of the three initial preparations (E-40, E-42, and E-44) was E-44. A trial scale-up of this method, E-46 was evaluated, but it did not perform as well as the original preparation. A stability trial, Figure 3 (below), also indicated that the E-46 preparation method was unsatisfactory. A new small scale preparation, E-49, had better activity than the previous preparations, and had better stability, Figure 4 (below). The scale-up of this material, EL-70, is even more active; a stability trial is currently in progress.

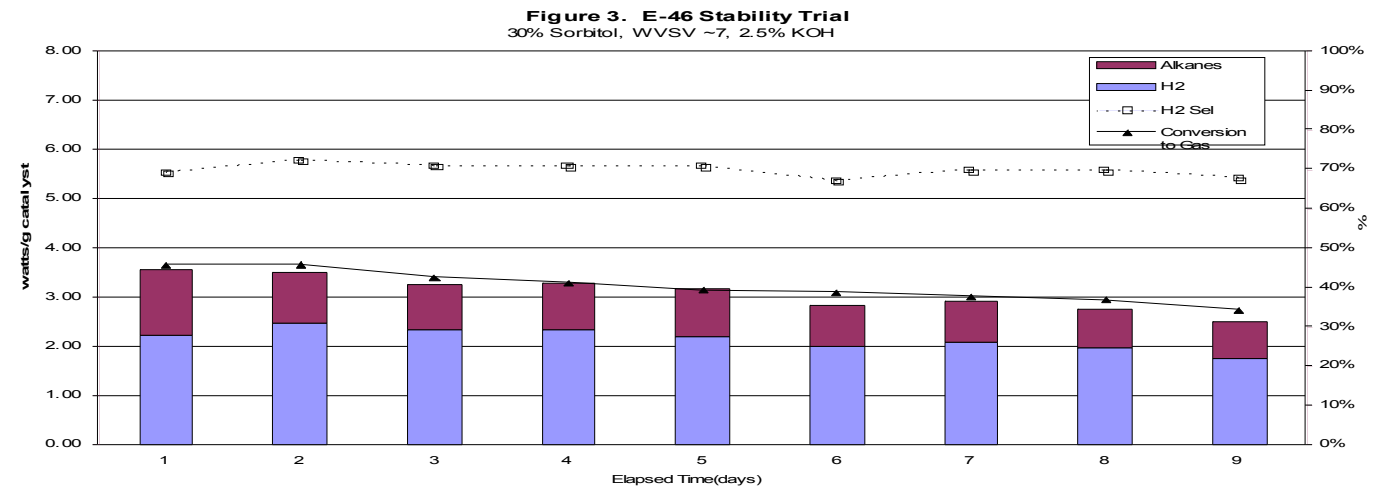




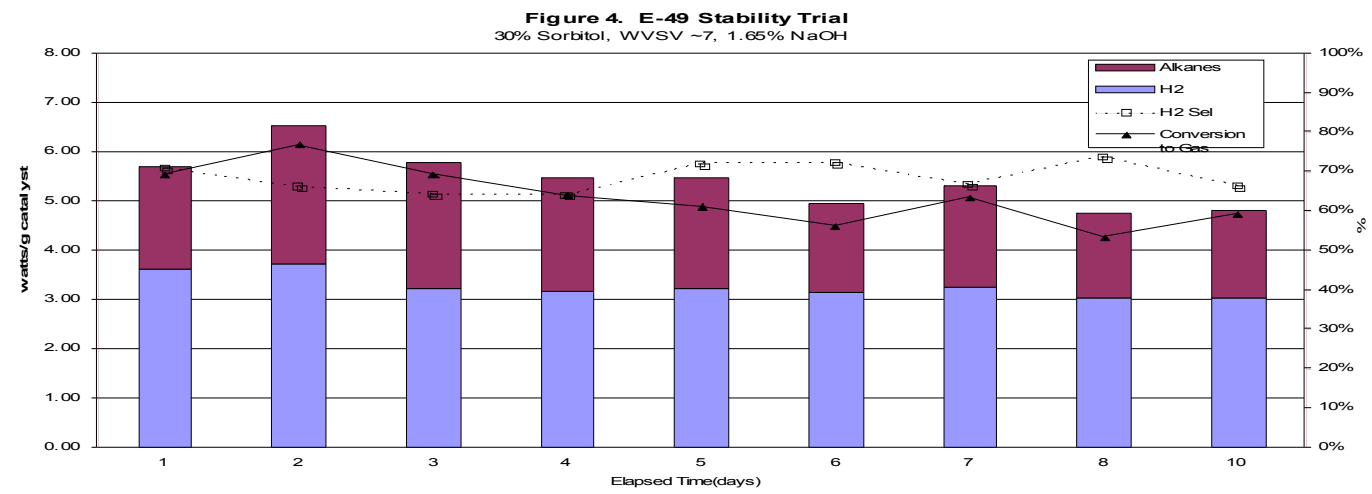

\section{Recycle System}

Virent conducted studies to determine the effects of recycling the liquid product from the water separator. In such a system, the only products are gas-phase products. The general schematic of this recycle system is shown in Figure 5 below. This system utilizes a pump to introduce a concentrated mixture of fresh feed to the recycled aqueous phase from the separator. The desired concentration of sorbitol fed to the reactor is controlled by the relative speeds of the fresh feed pump and recycle pump. The gas and liquid mixture out of the reactor is cooled down by a water condenser and passed to a water separator. The product gas is sent for GC analyses and the liquid is recycled back into the reactor.

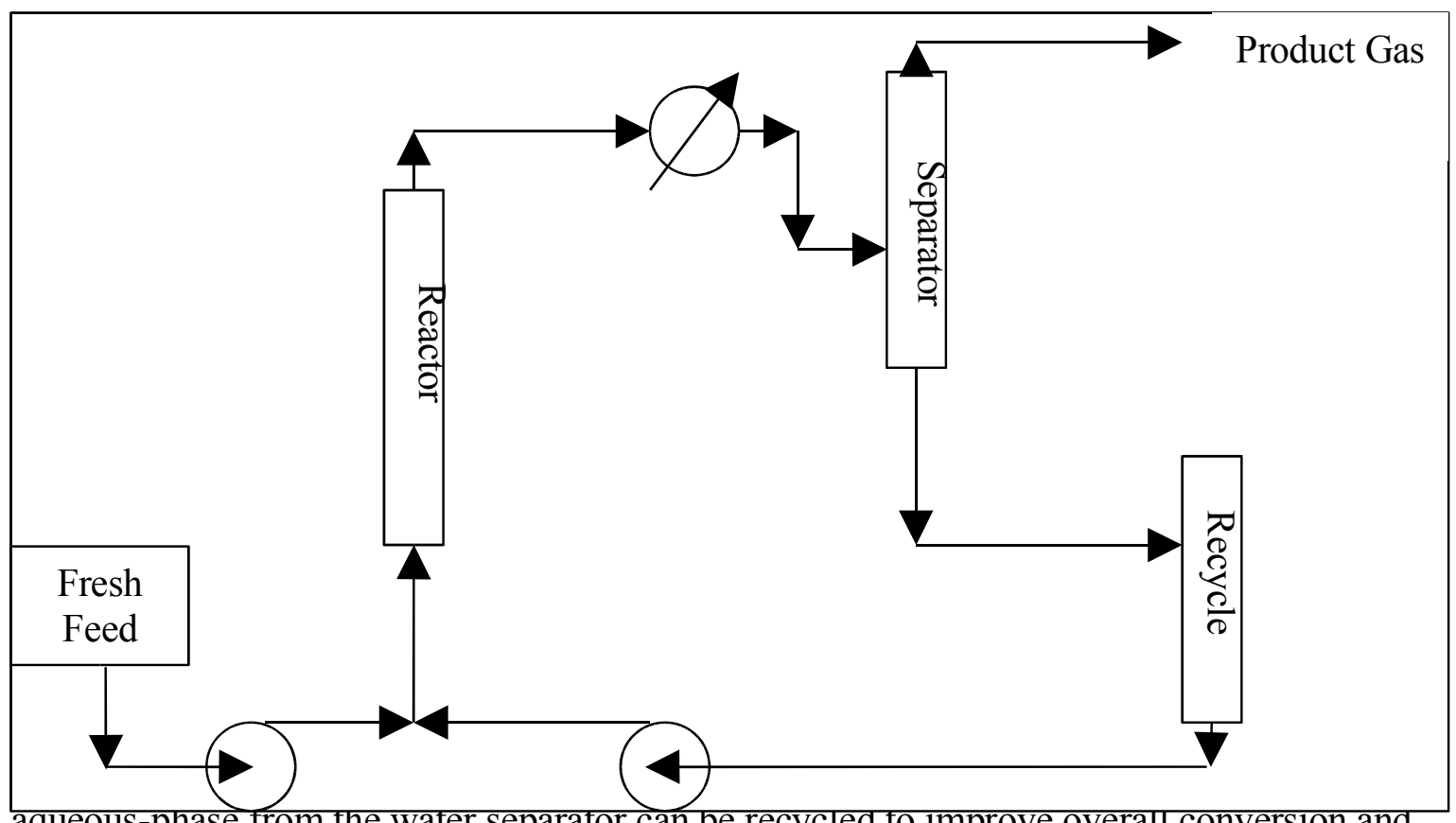

aqueous-phase from the water separator can be recycied to improve overall conversion and the addition of hydroxide can be either minimized or eliminated to maintain the desired reactivity. 
Figure 6 shows the result of first feeding a solution of $30 \%$ sorbitol with $\mathrm{NaOH}$ in the once through configuration during the first day of operation. The apparatus was subsequently run in the recycle mode with no further addition of $\mathrm{NaOH}$ and the combined feed to the reactor maintained at a concentration of $30 \mathrm{wt} \%$ carbon. Figure 6 shows the amount of hydrogen and alkane produced per gram of catalyst as well as the amount of sorbitol found in the reactor effluent. This figure shows that at $240 \mathrm{deg} \mathrm{C}$, not all the sorbitol was converted through the reactor. Accordingly, the reactor temperature was increased to 250 $\operatorname{deg} \mathrm{C}$ which allowed for complete conversion of the sorbitol as well as increased the amount of hydrogen and alkanes produced in the reactor.

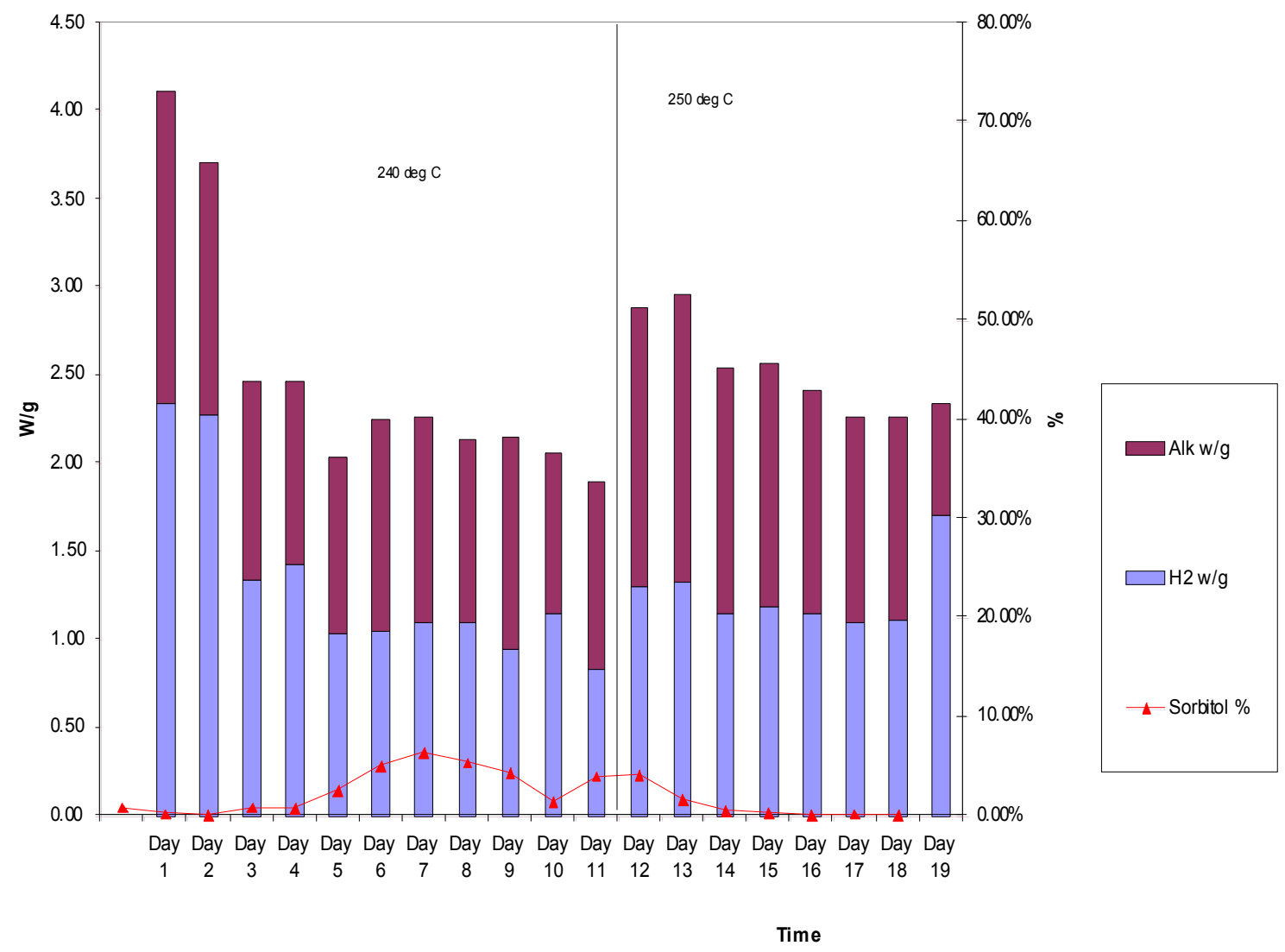

Figure 6 Conversion of 30 \% Sorbitol in Recycle Reactor

\section{Subscale Reactor Development and Operation}

Task 3 of this project was to design, build, and operate a subscale reactor system. For this Task, a multi-tubular integrated aqueous phase reforming reactor was designed, manufactured and tested. This multi-tubular reactor provided information needed for scaleup of the APR process. Goals of the multi-tubular bundle were to supply information on supplying heat to the reactor via combustion, feed and combustion gas manifolding and verification of design. The reactor heat was provided by a burner via homogeneous combustion of natural gas. The reactor implemented integrated feed flow distribution and combustion gas manifolding. 
The reactor had individual outlets and chillers for each catalyst zone for verification of proper feed flow distribution and combustion gas manifolding. The sampling setup allowed for complete gas sampling as well as individual gas sampling. Combustion control, safety shutoff system and data acquisition were performed on a Labview system. Reactor performance was tested with varying mixtures of sugars/glycols and water, WHSV (weight hourly space velocity), combustion temperature and combustion GHSV (gas hourly space velocity).

Testing of this reactor system started at the end of May, with initial results showing that the reactor could produce the equivalent of 1000 watts of gas from sorbitol. Furthermore, it was found that equal flow distribution could be achieve over the 4 tubes for both the liquid feed and the hot combustion gases used for heating. During June testing continued as is summarized below.

Figure 7 shows the power generated from each tube of this reactor system with a feed of sorbitol solution with other additives. Figure 7 shows the equivalent amounts of hydrogen and alkanes produced in watts per gram. Additionally, this figure also shows the product gas flow from each tube. Figure 7 shows that equal flow distribution was achieved over the 4 tubes for both the liquid feed and the hot combustion gases used for heating.

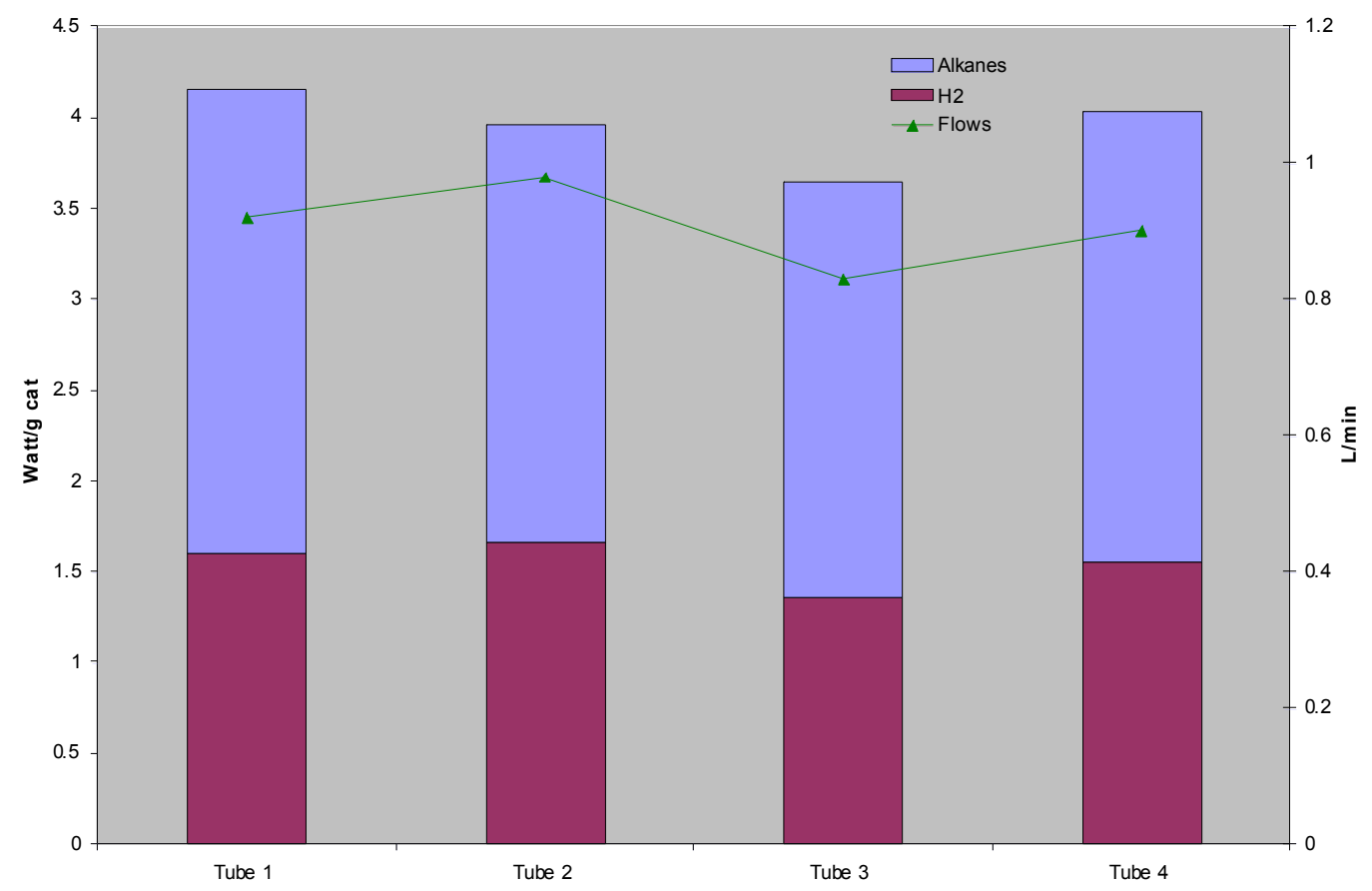

Figure 7 Conversion of Sorbitol in Multi-tube Reactor System 


\section{Conclusions}

New catalyst formulations with good activity continue to be found. Virent's search for a formulation with significantly better activity than the many "good" formulations should continue.

Virent's catalyst provider is making good progress in their attempts to scale up a catalyst preparation for use in the electric power generation pilot system.

Virent has shown that it is possible to run the APR in the recycle mode and that in this mode it is not necessary to add additional hydroxides to maintain reactivity of the catalyst.

Virent has built and operated a subscale reactor system and results from this system have verified the proposed reactor design for the APR system.

\section{FINAL WORK PERIOD - July - August 2005}

Work on this project continued through August, 2005. At the end of this reporting period, Virent completed the development of the catalytic reactor system necessary for reforming sorbitol, tested this reactor system with glycerol, designed, constructed, and tested a subscale reactor system that generated over 2000 thermal watts of hydrogen-rich fuel gas from the aqueous-phase reforming of glycerol.

Below please find a breakdown of the outcome of each of the tasks set forth in the original proposal:

\section{Task 1. Feedstock Sampling}

Under this task, ADM provided 110 gallons of commercial-grade sorbitol syrup to Virent. This syrup contained approximately $70 \mathrm{wt} \%$ solids with the remainder being water. ADM also provided analytical services to Virent in which samples of the aqueous and organic streams from Virent's test stands were analyzed by ADM. Catalysts and reactors were developed utilizing the ADM commercial-grade sorbitol.

\section{Task 2. Catalyst Development for Commercial-Grade Sorbitol}

Results of catalysts testing and reaction conditions testing have been reported in previous monthly reports for this project. Figure 1 shows a summary of the results of this investigation as a function of study time. The baseline for system performance is the published results from the University of Wisconsin [Cortright, R.D.; Davda, R.R.; Dumesic J.A., Nature, Vol. 418, p.964, 2002] in which a proof-of-concept investigation showed that complete conversion of $1 \mathrm{wt} \%$ solutions of ethylene glycol and sorbitol were obtained at weight hourly space velocities of $0.008 \mathrm{~kg}$ of oxygenated compound per $\mathrm{kg}$ of catalyst per hour. At these reaction conditions, the thermal efficiency of the system was such that it required more energy to generate the collected product gas than the energy obtained from the product gas. In subsequent developments at Virent Energy Systems funded under a 
NIST ATP grant, the performance of the APR system was improved such that complete conversion of the ethylene glycol to combustible compounds (hydrogen or alkanes) was obtained at a WHSV of $1.25 \mathrm{~kg}$ of ethylene per $\mathrm{kg}$ of catalyst per h. At these reaction conditions, the heating value of the resulting hydrogen-rich fuel gas stream was $55 \%$ of the lower heating value of ethylene glycol. Figure 1 shows the improvement of the APR process for processing sorbitol during the 10 months of this project. This figure shows that the reactor performance was improve such that complete conversion of sorbitol to combustible compounds could be obtained at a WHSV of $1.78 \mathrm{~kg}$ of sorbitol per $\mathrm{kg}$ of catalyst per $h$. The heating value of the resulting hydrogen-rich gas stream was $71 \%$ of the lower heating value of sorbitol.

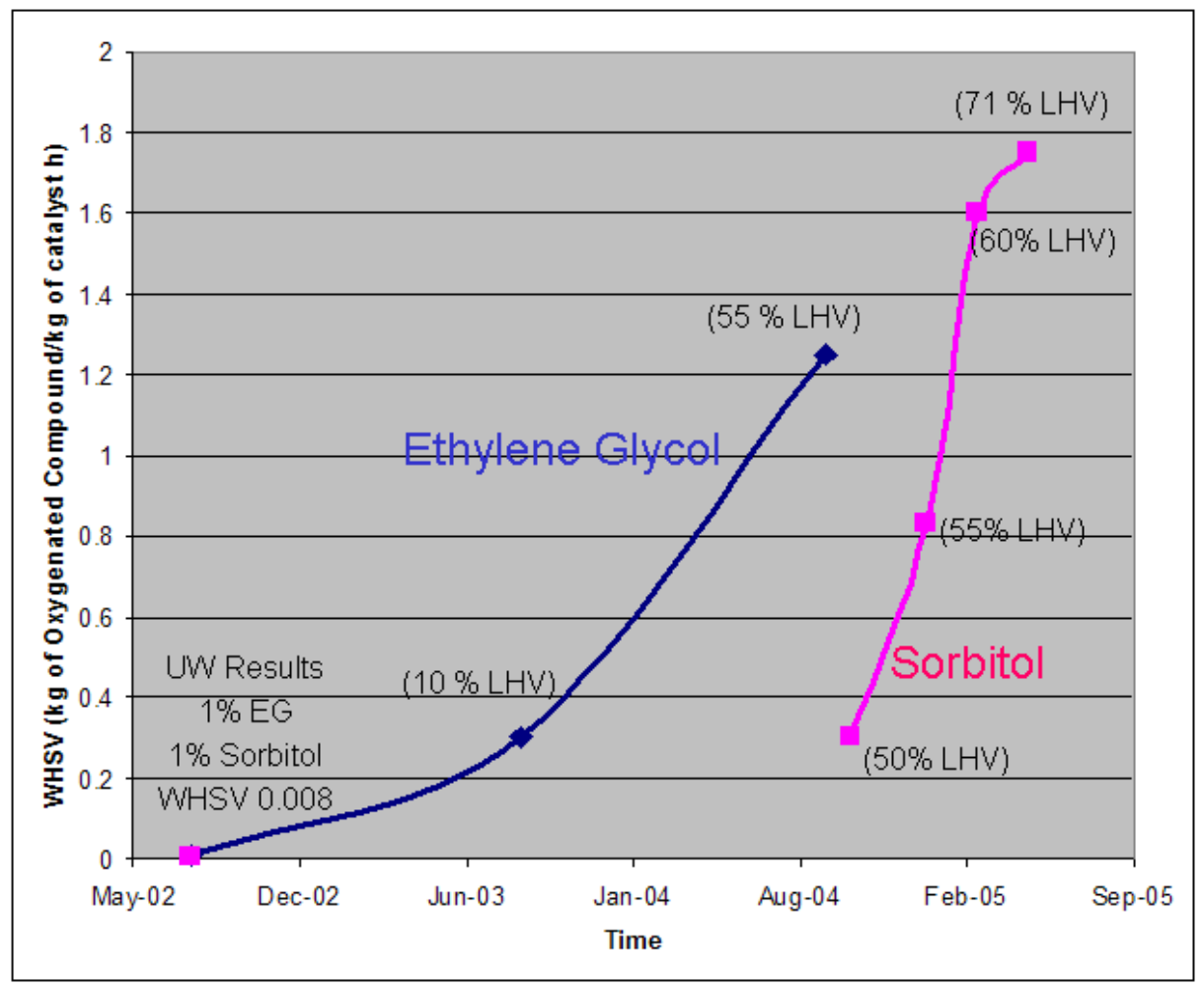

Figure 1. Development Progress for APR Reactor System

As reported in the July report, Virent developed catalyst compositions and pretreatment conditions that allow the catalyst to perform for periods of 45 days without significant changes in catalyst performance.

\section{Task 3. Catalyst Development for Glycerol}

ADM utilized significant amount of in-kind resources to perform the chemical analysis of aqueous and organic streams provided by Virent. Accordingly, they did not have the resources to synthesis the necessary lower grade sorbitol stream in their facilities and did not have an easily way to obtain such a stream. Furthermore, Virent had been 
approached by numerous biodiesel producer interested in utilizing the APR process as a method to convert waste glycerol from their processing plant to value-added hydrogen-rich stream. Virent tested the reactor system developed for sorbitol with USP-grade glycerol and found the system performed even better with glycerol (see Table 1 below).

Task 4. Subscale Reactor Development and Operation

Virent has designed and fabricated a proprietary multi-tubular integrated aqueous phase reforming reactor. The reactor implements both integrated feed flow distribution and heating using hot gas. In this case the reactor was tested on test apparatus that utilized electrically heated hot air as the energy source. This reactor was twice the size of the reactor and loaded with 360 grams of EL-70 catalyst provided by the catalyst supplier. Table 1 shows the testing results for this reactor utilizing a proprietary glycerol and water solution. This table shows that this reactor system was able to generate more than 2000 thermal watts of hydrogen rich fuel gas at a thermal efficiency across the reactor of nearly $75 \%$.

Table 1 Performance of Multi-Tube Reactor for the Conversion of Glycerol

\begin{tabular}{|c|c|c|c|c|c|c|c|c|c|}
\hline $\begin{array}{c}\text { WHS } \\
\text { V }\end{array}$ & $\begin{array}{c}\text { Reactor } \\
\text { Temperature } \\
\left({ }^{\circ} \mathrm{C}\right)\end{array}$ & $\begin{array}{c}\text { Power } \\
\text { Generated } \\
\text { (watts) }\end{array}$ & $\begin{array}{c}\text { Energy } \\
\text { Required } \\
\text { by } \\
\text { Reactor } \\
\text { (watts) }\end{array}$ & $\begin{array}{c}\mathrm{Rx} \\
\text { Thermal } \\
\text { Efficienc } \\
\mathrm{y}\end{array}$ & $\begin{array}{r}\% \\
\mathrm{H} 2 \\
\end{array}$ & $\begin{array}{c}\% \\
\mathrm{CO} 2 \\
\end{array}$ & $\begin{array}{c}\% \\
\text { Alkane } \\
\mathrm{s} \\
\end{array}$ & $\begin{array}{c}\text { Glycerol } \\
\text { Conversio } \\
\mathrm{n}\end{array}$ & $\begin{array}{c}\text { Conversion } \\
\text { to } \\
\text { Combustibles }\end{array}$ \\
\hline 3.70 & 241 & 1537 & 392 & $74.5 \%$ & 51.3 & 37.2 & 11.5 & $100 \%$ & $62.5 \%$ \\
\hline 5.56 & 238 & 2019 & 511 & $74.7 \%$ & 51.8 & 37.0 & 11.2 & $100 \%$ & $61.7 \%$ \\
\hline 6.31 & 243 & 2112 & 531 & $74.9 \%$ & 52.5 & 37.9 & 9.6 & $100 \%$ & $48.9 \%$ \\
\hline
\end{tabular}

This multi-tube reactor will be manufactured as a module and multi-modules will be utilized in an APR system that will generate fuel gas for an internal combustion engine driven generator. Heat from the hot exhaust gas from the ICE will be extracted and used in the APR reactor system. Virent has completed the final designed of this integrated APR/ICEGenset and is beginning fabrication. In this design, the aqueous-stream from the water separator will be recycled back to reactor and fresh feed will be mixed with this recycle stream. This combined APR/ICEGenset is designed to deliver $5 \mathrm{~kW}$ of electrical power. This system will be connected to the Madison, Gas and Electric (MGE) grid at Virent's headquarters in Madison, Wisconsin. This $5 \mathrm{~kW}$ integration project, which funding for both the system and integration to the grid were provided in part by MGE. Catalysts for this application will be purchase from the catalyst provider based on the EL-70 formulation tested in this project. 


\section{Conclusions}

Virent has successfully developed a reactor system that effectively converts sorbitol to a hydrogen-rich stream using the APR process. Furthermore, Virent has designed, built, and demonstrated a catalytic reactor that generated more than 2000 thermal watts of hydrogen-rich fuel gas via the aqueous-phase reforming of glycerol. This catalyst reactor was nearly $75 \%$ thermally efficient. Virent will utilize this reactor system in a combined APR/ICEGenset to validate the effectiveness of the APR process in a live environment.

\section{Products and Technology Transfer Activities}

\section{MGE Unit}

As noted above, Virent designed and developed a complete APR system that will utilize the reactor designed in this project to generate a hydrogen gas via the aqueous-phase reforming of either glycerol or sorbitol. The system was funded in part by MGE, the local utility in Madison. The system integrates a Virent GEM unit with a hydrogen/natural gas fueled generator set provided by City Engines, Inc. (Reno, NV). The system has demonstrated the ability to deliver $6 \mathrm{~kW}$ of power to the MGE grid since its startup at the beginning of this year at Virent's location in Madison, Wisconsin. To enable this power output, the APR system generated $2.2 \mathrm{kgs}$ of hydrogen and alkanes per hour. The APR systems can be designed to deliver predominantly hydrogen or alkanes (i.e. natural gas, ethane, butane and propane), or a customized blend of these fuels. Virent refers to these various biomass-generated streams as Supernatural ${ }^{\mathrm{TM}}$ fuels. Measurements of the exhaust stream confirm the emissions from the engine are excellent. With a hand held emission detection unit, NOx emissions were measured at $4 \mathrm{ppm}$ with the Supernatural fuels, well below the $17 \mathrm{ppm}$ measured by the same unit when the system was running on natural gas. Particulate measurements should be almost zero as has been demonstrated on other HCNG internal combustion engines.

The system operated on pure glycerin. In the future, the Company will use a lower grade of glycerin that is generated as a byproduct of the biodiesel production process. Virent also intends to use sorbitol as a feedstock for this initial unit.

The system (pictured below) was run uninterrupted for a period of two weeks. At that point, it was shut down in large part due to the requirement for constant oversight from Virent personnel. For a 18 person company, this requirement was overwhelming our ability to run the system without compromising other projects. As a result, Virent is actively working on automating the system to enable operation without immediate human oversight. Over the next 18 months, this system will generate needed reliability and performance data for an APR system in a live environment.

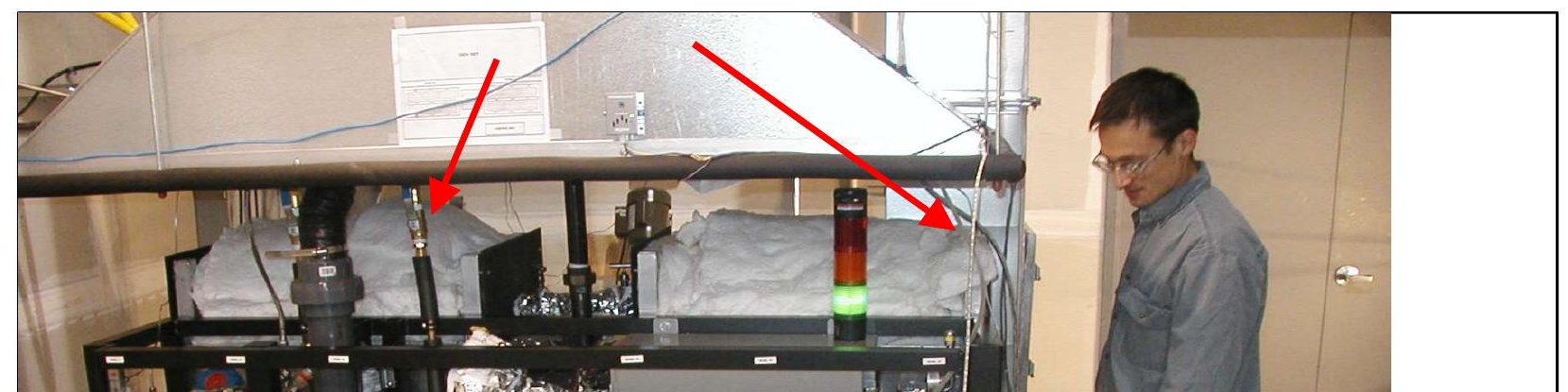


- With the recent investment, the Company has begun to hire required talent to support near term commercialization of the APR technology. One of the first key hires is Mr. Greg Keenan, former Air Product's Business Development Manager, Future Energy Solutions. Mr. Keenan has extensive project management, product development and sales and marketing experience that will by invaluable to Virent as it continues to progress its business.

- Part of the equity funding will be dedicated to addressing the remaining technical challenges for the APR process. The Company needs to demonstrate an APR system is capable of delivering reliable and sustainable performance for a longer period of time (a year at a minimum). Up to 150 days have been demonstrated with lab scale system, but it is important that durability also be evidenced in a larger capacity system in a live environment. Once this is demonstrated, Virent will be in a position to move the APR system immediately into product mode.

- Presently, the Company has twenty employees and 2005 revenue was $\$ 1.3 \mathrm{M}$. Perhaps more importantly, Virent has advanced its process significantly since the inception of the ATP grant. Much of the technical progress (which, in turn, attracts the commercial interest) is the direct result of the catalyst developments and performance improvements that were made under this program. The investment and alliance interest is attributable to the progress the company has made with the APR process.

- There is growing global awareness of the need to find alternative sources of sustainable fuel in light of the political and economic consequences of continued dependence on oil. The APR process held the promise of offering a cost effective, energy efficient method for generation of fuels form renewable resources in 2003. However, it did not have adequate capital to advance the process to a commercial demonstration. This grant provided needed funding to help fill this gap. The end result is a Company that has huge potential to deliver cost effective renewable fuels to the world. Within two years, the Company hopes to have not only multiple demonstration projects in place, but also a field ready system ready to be employed in a number of different environments. Ultimately, Virent desires to be viewed as the preferred worldwide technology source for low cost renewable gas and liquid fuels. 


\title{
Press Release
}

FOR IMMEDIATE RELEASE:

January 26, 2006

\author{
Virent Energy Systems, Inc.
}

3571 Anderson St., Ste. 209

Madison, WI 53704

Phone: 608-663-0228 (Ext. 210)

Fax: 608-663-1630

\author{
Contact: Eric Apfelbach \\ Successful Startup for 10kW Virent System that Generates Power from
}

\section{Biomass}

MADISON, WIS. - Virent Energy System, Inc. (Virent) today announced that it has successfully started up the first ever demonstration system capable of directly converting sugars and glycerin into power. The system, purchased by Madison, Gas \& Electric (MGE), is based on Virent's patented Aqueous Phase Reforming (APR) process, a carbon neutral, one-step method for on-demand production of hydrogen, natural gas and/or other fuel gases for distributed power systems from widely available renewable biomass.

The MGE system integrates a Virent APR System with a hydrogen/natural gas fueled generator set provided by City Engines, Inc. (Reno, NV). The system has demonstrated the ability to deliver a minimum of $10 \mathrm{~kW}$ of environmentally friendly power to the MGE grid since its startup at the beginning of this year at Virent's location in Madison, Wisconsin. Virent was able to customize the gas production from its APR system to deliver desired compositions of hydrogen, natural gas and other fuel gases to the generator set. The system currently operates on pure glycerin. In the future, the Company will use a lower grade of glycerin that is generated as a byproduct of the biodiesel production process. Virent also intends to use sugar in the form of sorbitol and glucose as a feedstock for this initial unit. Over the next 18 months, this system will generate needed reliability and performance data for an APR system in a live environment. 
Virent's APR system offers a cost effective method for low temperature production of hydrogen and/or fuel gas. By demonstrating the capability of localized, on-demand fuel delivery, the system is a promising first step to providing a reliable method for renewable fuel generation from a variety of widely available biomass sources. The APR systems can be designed to deliver predominantly hydrogen or alkanes (i.e. natural gas, ethane, butane and propane), or a customized blend of these fuels. Virent refers to these various biomassgenerated streams as Supernatural ${ }^{\mathrm{TM}}$ fuels. This system design will target a number of opportunities, ranging from stationary power systems, industrial hydrogen, renewable fuel stations or, longer term, mobile applications.

Dr. Randy Cortright, Chief Technical Officer and Founder of Virent, pointed to the extensive laboratory and design work that went into the system as the key to this successful startup. "This system is a validation of all of our work over the past couple of years on developing the APR process. We have told collaborators about the promise of this technology, and now we have a working system to demonstrate that APR is capable of becoming a viable production system. I believe this is a crucial first step to delivering a reliable, cost effective system for production of renewable fuels. Through our efforts on this system, we now have a much fuller understanding of the process that will lay the groundwork for even more compelling APR units in the near future."

"We are proud to have played a role in the first ever demonstration of direct conversion of biomass derived liquids to fuels. This furthers our commitment to finding clean sources of fuel from renewable sources. We think the Virent process holds the potential for reshaping how people think about renewable energy. We are excited to be a part of this effort with Virent," said Gary Wolter, MGE Chairman, President and CEO.

Eric Apfelbach, Chief Executive Officer of Virent, commented on the performance of the system, "The level of excitement generated by this APR system start-up is very high because the system greatly exceeded all of our targets for power output and performance with an integrated ICE. It is very clear that the APR system represents a compelling option for cost effective, clean, distributed energy generation. With the global availability of $\mathrm{CO} 2$ neutral feedstocks and the ability to fuel microturbines, fuel cells, and ICEs in an unteathered fashion, the market opportunities are enormous. We are proud of Virent development team and appreciative of the support provided by MGE."

The Virent website (http://virent.com) will shortly have additional information on this unit, and a more detailed overview of the system developed by the Energy Center of Wisconsin will be available in mid-February at http://www.ecw.org/biomass2power. Virent plans to ship additional beta units to third parties over 2006 for further field testing.

Virent Energy Systems, headquartered in Madison, WI, is dedicated to enabling the widespread, economical use of renewable biomass to produce truly carbon neutral fuel for power systems and mobile applications. The Company is a member of the American Council on Renewable Energy, National Hydrogen Association and Upper Midwest Hydrogen Initiative. 
MGE is a public utility that generates and distributes electricity to nearly 132,000 customers in Dane County and purchases and distributes natural gas to more than 129,000 customers in seven south-central and western Wisconsin counties. MGE has served the Madison area since 1896. 
Technical Contact:

Dr. Randy D. Cortright

CTO/Executive Vice President

Virent Energy Systems, INC.

3571 Anderson Street

Madison, WI 53704

Phone: 608/663-0228 Fax: 608/663-1630

e-mail: randy_cortright@virent.com

\section{Additional Key Participants:}

\section{Research Partner Contact:}

Jeff Moore

Business Development Manager

Virent Energy Systems, INC.

3571 Anderson Street

Madison, WI 53704

Phone: 608/663-0228 Fax: 608/663-1630

e-mail: jeff_moore@virent.com
Business Contact:

Kathryn Schiedermayer

Project Manager

Energy Center of Wisconsin

455 Science Drive, Suite 200

Madison, WI 53711

Phone 608/238-8276 Ext. 147

Fax: 608/238-8733

e-mail: kschiedermayer@ecw.org

\section{Research Partner Contact:}

Charles A. Abbas, Director

Research and Development

Archer Daniels Midland Company

1001 N. Brush College Rd.

Decatur, IL 62521

Phone: 217/451-2460 Fax: 217/451-2927

e-mail: abbas@admworld.com 